\title{
Local, Sustainable, Small-Scale Cellular Networks
}

\author{
Kurtis Heimerl, Shaddi Hasan. Kashif Ali, Eric Brewer, Tapan Parikh \\ University of California, Berkeley \\ \{kheimerl; shaddi; kashif; brewer @cs.berkeley.edu\} parikh@ischool.berkeley.edu
}

\begin{abstract}
Over five billion people are active cellular subscribers, spending over a trillion dollars a year on communications. Despite this, hundreds of millions of people are still not connected.

Implicit in these networks is a top-down design, with large nationscale telecommunication firms deciding when and where coverage will be available. This is enforced by the large capital investment required to run cellular systems; base stations can cost upwards of US $\$ 100,000$ and require expensive related core infrastructure. Recent technological innovations have enabled much cheaper cellular equipment; a base station now costs around US\$10,000 and requires none of the other related systems.

This reduction in cost is enabling new models of cellular telephony. Small organizations are suddenly capable of being service providers. In this work we ask, "How successful would bottom-up cellular networks be?" Essentially we argue for and demonstrate a local cellular network, utilizing existing infrastructure (e.g., power, network, and people) to operate at much lower cost, with less required capital, bringing coverage to areas not traditionally able to support cellular deployments. This network also provides sustainable employment and revenue to local entrepreneurs and services for the local community.

We demonstrate the value of this concept by conducting an ongoing six-month long field deployment in rural Papua, Indonesia, in partnership with local NGOs. This network is currently live, with 187 subscribers sustainably providing US\$830 per month in revenue (US\$368 in profit) for the operator and employment for three different credit sellers in the village. We also show that this network provides a valuable service to the community through usage logs and user interviews.
\end{abstract}

\section{Categories and Subject Descriptors}

K.4.M [Computers and Society]: Miscellaneous

\section{General Terms}

Economics, Experimentation, and Legal Factors

\section{Keywords}

Information and Communications Technology for Development

\section{INTRODUCTION}

Over six billion people use cellular phones [20], impacting the fundamental economics of their lives [22] and their communications with friends and family [7]. This impact is particularly large among

\footnotetext{
Permission to make digital or hard copies of all or part of this work for personal or classroom use is granted without fee provided that copies are not made or distributed for profit or commercial advantage and that copies bear this notice and the full citation on the first page. To copy otherwise, to republish, to post on servers or to redistribute to lists, requires prior specific permission and/or a fee.

ICTD 2013, December 0710 2013, Cape Town, South Africa

Copyright is held by the owner/author(s). Publication rights licensed to ACM. ACM 978-1-4503-1906-5/13/12 ...\$15.00.

http://dx.doi.org/10.1145/2516604.2516616
}

the disadvantaged; Agüero et al. [3] found that, for users at the "Bottom of the Pyramid", telecommunications displayed the usage patterns of a necessity; as total income falls the share spent on telecommunications increases, with some disadvantaged groups spending upwards of $50 \%$ of their income on communications.

Unfortunately, hundreds of millions of people, primarily in rural areas, still lack coverage. The International Telecommunications Union (ITU) estimates that $95 \%$ of people in East Africa currently without network coverage are in rural areas without grid power [21]. Galperin et al. [13] suggest that there is also a structural issue; the only organizations currently capable of deploying cellular networks are major telecommunications firms. Despite subsidies, these firms' strong profit motives limit their investment in rural connectivity, leaving areas that are outside of existing infrastructure or have too sparse a user base without coverage. As an alternative model, Galperin points to microtelcos: small community, NGOowned, or otherwise independent telecommunications firms that exist in some countries in Latin America.

The current model of cellular network deployment is top-down, with governments and large national-scale telecommunication corporations deciding who gets coverage. We instead propose to build bottom-up: local entrepreneurs or NGOs owning and operating their own cellular services for the local population (sometimes called "inverse infrastructure" [11]). From an economic perspective, researchers have found that small-scale local actors can actually have lower costs than larger ones by leveraging existing infrastructure [13]. Similarly, decentralizing these networks could potentially empower the local community, increasing opportunities and freedom [29].

We envision cellular networks that are:

- $\quad$ Local, operated primarily by agents within the community;

- $\quad$ Built with existing local infrastructure when available;

- Low cost, financeable by small entrepreneurs or NGOs; and

- $\quad$ Sustainable, with profit staying in the community.

To evaluate this design, we implemented a small-scale cellular network and deployed it in the village of Desa in rural Papua, Indonesia, in partnership with two local NGOs. This network provides mechanisms for local operation including buying and provisioning SIM cards, buying and selling credits, checking credit levels, communicating with in-network friends via SMS or voice, and out of network contacts via SMS. It is jointly owned and operated by both a local education-focused NGO and a for-profit wireless Internet service provider, providing both a base of operations and the technical knowledge required for sustainable deployment. This network operates profitably, with our NGO partner charging for both SIM cards as well as credits in the network.

We monitored the transactions in our network from February 11th, 2013 (the opening of the network for sales) until August 12th. In that time, the network serviced 187 users; handled over 49,000 outbound (out of network) SMS, 42,000 inbound (into network) SMS, 24,000 local (in-network) SMS, and 12,000 local calls; and generated over US $\$ 5,000$ in revenue for the operators. We also saw over 20,000 local service requests, including credit transfer, credit check, and others, some generating revenue for community members. These results 
demonstrate the feasibility and sustainability of local cellular networks. Our core contributions are:

- The design of local cellular installations, building off of prior non-technical work [13];

- The implementation of a cellular network of that design; and

- The evaluation of the design and its sustainability through a deployment with NGO partners in rural Papua, Indonesia.

\section{RELATED WORK}

Small, local cellular operators are common in some parts of the developed world. As an example, the Competitive Carriers Association [9] is a trade organization for such operators in the United States. These networks often predate the rise of carriers who now dominate national markets. Though the scale of these local operators is much larger than ours (usually tens to hundreds of towers, instead of one), we argue for a similar model: smaller operators serving their communities profitably.

Galperin et al. [13] explored community owned communication networks in Latin America, arguing for the feasibility of similar cellular systems. We build on this vision by implementing and evaluating an instance of a local cellular system.

Some large aid agencies have proposed using universal service obligation (USO) funds for small-scale extensions to traditional networks maintained by local people [23]. In this design, the carriers reap all of the profit from the installation, in contrast to our approach which keeps profits with local actors.

Researchers have also explored the use of cellular networks in rural areas. Heimerl et al. [17] and Anand et al. [5] both proposed building custom OpenBTS-based networks for rural areas. Zheleva et al. [36] implemented one such system, deploying it in rural Zambia and supporting local communications. Though these designs and implementations inform and improve our system, our goal is fundamentally different: we build and demonstrate a sustainable local cellular network.

Lo3 [12], Serval [14] and The Village Telco [1] use WiFi meshes to build low-cost community telephony networks, primarily serving voice. These systems utilize custom-made hardware, smart phones, or distributed mesh radios. We use commodity low-cost GSM cellular phones to ease adoption, centralize our equipment, and to ease deployment and reduce maintenance.

With the incredible adoption of cellular systems, both industry and academia have investigated the impact of telephony on rural and developing populations. The International Telecommunications Union (ITU) has published aggregate usage statistics [20] as well as lower-level analyses of the cost of running a rural cellular site [21]. The GSM Association has done similar work [15].

Researchers have also analyzed cellular use. Jensen [22] found that the installation of cellular towers in Kerala benefited the users by reducing information asymmetries. Waverman et al. [34] and Deloitte [10] found other benefits in many other developing areas of the world. In general, researchers note that the cell phone has been an important technology in the developing world $[7,19]$. These results motivate our desire to enable telecommunications.

\section{CONTEXT}

In mid-2012, a wireless Internet service provider in rural Papua, Indonesia contacted us and asked us to visit and install a low-power GSM base station (BTS). This was the beginning of our journey into Papua. Note that all names are anonymized.

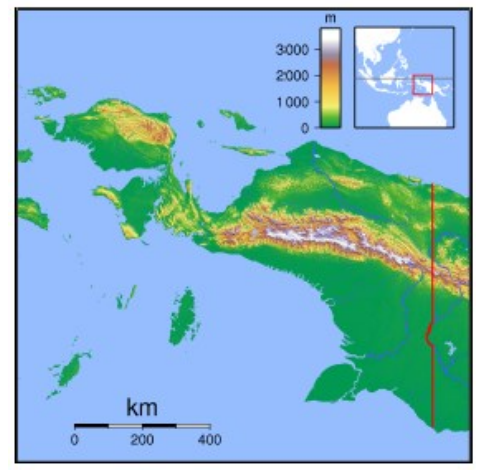

Figure 1: Papua, Indonesia

\subsection{Papua}

"Papua" (Figure 1) refers to the western half of New Guinea (and nearby islands) in the Southwest Pacific. Claimed by the Dutch since the $1800 \mathrm{~s}$, it has been a province of Indonesia since being officially annexed in 1969. The 19th and 20th centuries saw turbulent transitions from a pre-colonial situation of small polities with shifting inter-regional relations, to the Dutch project of colonial state-building, and finally to the current context of incorporation into Indonesia [27]. Often portrayed as "isolated", developments in Papua are historically connected to maneuvers at centers of global power such as the UN and the US [28]. Major international resource companies are active in Papua, notably at the world's largest gold and copper mine located in the western Highlands and owned by US-based Freeport MacMoran. Various forms of unrest have waxed and waned through the colonial and post-colonial periods [28]. In 2003, Papua was divided into two provinces, "West Papua" and "Papua", with the independent state of Papua New Guinea to the east. Our work is in the Province of Papua.

Despite being on the second largest island on earth, there are only 2.8 million people in the province, just 8.9 people per square kilometer. The population, however, is growing rapidly due to settlement of migrants from other Indonesian islands. The province faces many societal ills: high infant mortality (56.6 per 1000 [6]), low life expectancy (63.07 [6]), low Human Development Index score (65.36 [30]), and a high number of HIV/AIDS cases [8]. These issues are often viewed by locals as connected to wider patterns of exclusion from the benefits of official development programs [8].

\subsection{The Highlands}

Our intervention takes place in the Central Highlands of Papua. Despite a long history of regional trade connections [25], the area had no contact with Westerners until the 20th century, when a scientific expedition happened upon the population in 1938. Following this "discovery", the region was host to extensive missionary activities and the establishment of Dutch police posts.

The Central Highlands region has undergone dramatic transformations since the first development programs began in the mid 1900's. Wamena, the region's commercial and administrative center, is now a bustling town with a rapidly growing population and economy, targeted with major state infrastructure investments, and drawing migrants from the surrounding rural area and distant Indonesian islands. These infrastructures are concentrated in the town itself; there are no roads connecting to Papua's other cities, and virtually all goods are transported in by air. A number of companies provide Internet. A local provider, called WamenaCom, run by an Indonesian and an American, is our technical partner for this installation. Connectivity in the highlands relies on satellites; there are no wired connections to other Papuan cities, nor off Papua itself. 
Infrastructure expansions have recently proliferated outside Wamena, specifically in places selected as new administrative centers. A number of nearby villages have electricity; diesel generators are commonly present and occasionally running in government buildings and homes of wealthier people. However, villages distant from Wamena generally lack village-wide communications or power infrastructure. We installed our network in one such village, Desa.

\subsection{Desa}

Desa is located four-hours drive from Wamena and has neither cellular network nor village-wide electricity. Administratively it is the seat of a district and thus is the site of government buildings, a police station, a military command center and post, a health clinic, two churches and a mosque, a produce market, shops, government schools, as well as a church-owned private primary school. We have been unable to find demographic data for the area; our estimates place Desa's population as 1,500 and the district's as 10,000. While a majority of the population is indigenous, there is a significant population of migrants as well. The population includes a number of civil servants, church workers, police officers, and soldiers. Agricultural production is the backbone of the regional economy: farmers harvest produce for subsistence and for sale at nearby markets. Desa's economy is shaped by its status as a district center, with cash available from salaries, institutional budgets and produce sales. Still, Desa is economically and administratively subservient to other centers, in particular Wamena and the regency capital, both located several hours drive away.

As an early regional center of Western missionization and Dutch colonial state building, Desa has partially retained its status as a center of administration, commerce, and church organization. The availability of commodities brought by missionaries in the 1950s led Desa to become a hub for regional trade [25]. Patterns of local authority are linked to the history of missionary education, and the church plays a large role in the networks of patronage and obligation that structure local politics. The church-owned school Misionaris Sekolahin (MS) is our partner in Desa. The school is funded through donations from other countries (primarily the US) and is run by an American couple (Regis and Nancy) who have lived in Papua for over a decade.

\subsubsection{Infrastructure}

Prior to our arrival, Misionaris Sekolahin (MS) installed a $5 \mathrm{kVA}$ micro hydro generator that powers numerous pieces of equipment: tens of light bulbs, ten laptops, a projector, refrigerators, and other smaller loads. This hydro is on from 6AM to 10PM each day; it must be stopped to allow the water reservoir to recover.

MS also maintains a VSAT Internet connection. Internet access was primarily used by teachers to keep in contact with their friends and family outside of Desa. It was also used for educational purposes, as teachers download informative YouTube videos or share Wikipedia information. This Internet connection was shared via a switch connecting multiple WiFi routers: one local to the school, one long distance link to a nearby community, and one large omnidirectional link for village access. While network access was originally controlled by just a shared WEP key, during our time in Desa they added a Mikrotik hotspot system. A small battery bank with 4 deepcycle batteries was used to power the VSAT (and a printer/copier) when the hydro was down.

\subsection{Deployment}

In mid-October 2012, we flew to Wamena to join WC in bringing cellular access to Desa. WC had been supporting MS for years, providing technical support for the VSAT installed in Desa. This VSAT was intended for school business, but half of the traffic is actually Facebook. This is accepted, as Regis believes that the teachers will leave if they can't communicate with their families.

The team (researchers, WC, MS) decided that the network will be owned by WamenaCom, with most profits returning to MS as payment for hosting and protecting the equipment. WC provides maintenance in the event of hardware issues, with the researchers resolving any software problems.

\subsubsection{User Base}

Estimating the potential user base in Desa is challenging. We conducted numerous informal interviews and learned that phones are prevalent, despite the lack of coverage. Users claimed to primarily use them for entertainment purposes.

However, due to a quirk of GSM's design, we were able to measure the number of unique phones in Desa during the period of our study. Phones will attempt to connect to any BTS at all if signal is unavailable; this is to provide emergency services. We recorded all such attempts to connect for the month of January 2013. During this time period we had 1060 unique handsets attempt to connect to our BTS. 356 of these were present for five or more days, indicating a sustained presence. Our findings understate total handsets, as many users have their handsets off while in Desa. These results indicate that we have a potentially large customer base available.

\subsubsection{Preparation and Activation.}

Though we arrived in Papua with a mostly functional system in late October 2012, we spent months resolving technical and social concerns before activating the system. Technical concerns included interconnection failures (with the global telephony system), a drill intersecting a motherboard, and building our billing and management systems. Our social concerns involved community meetings asking for feedback and long-term beta tests among some influential villagers. This allowed us to modify our technology to better suit the community and reduce problems before we had paying customers. Eventually, issues were resolved and the system stabilized. On February 11 th, the network opened for business.

\section{SYSTEM}

We built an entire telecommunications company worth of infrastructure: hardware, billing, and services for our partners and users. The design of our system followed three key principles:

- $\quad$ Simplicity: Minimize potential failure points;

- Familiarity: Mimic existing networks when appropriate; and - Locality: Involve the community in design decisions.

\subsection{Hardware}

Traditional cellular hardware is complicated; instead we wanted a smaller, lighter, more flexible system. OpenBTS [24] allows us to do this; it eschews the need for a variety of related infrastructure and instead allows operators to build a complete GSM base station using only a commodity PC and appropriate radio equipment. Here we detail all of the hardware required for running our rural telco, including the base station and tower.

\subsubsection{Base Station}

We purchased a 10W Range Networks 5150 BTS and mounted it in a weatherproof box acquired in Papua. We added a $24 \mathrm{~V} \rightarrow 12 \mathrm{~V}$ voltage regulator to insulate the machine against power failures and fluctuations [31]. We tower-mounted the base station to reduce cabling and RF loss and protect the hardware from theft. The completed installation is shown in Figure 2. The BTS was plugged into WC's switch for Internet access and attached to their battery bank for overnight power. Two batteries and a larger battery charger were installed to support the extra power draw from the BTS. 


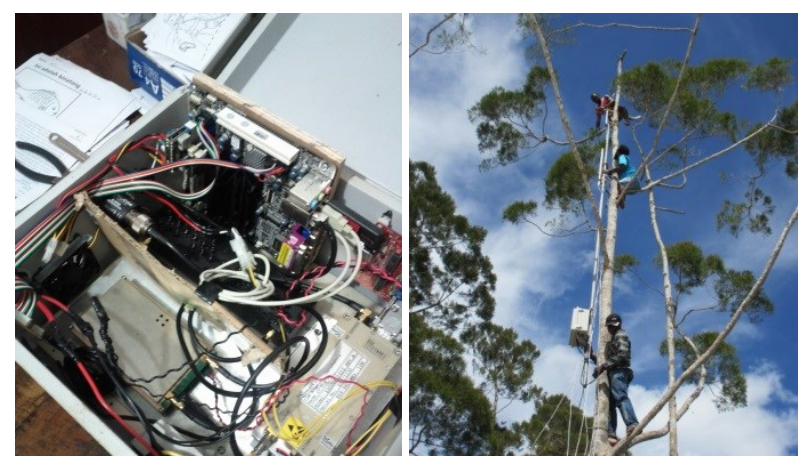

Figure 2: Our Base Station and its installation.

\subsubsection{Tower}

Building a tower out in the village is a difficult proposition; concrete and other building materials are heavy and expensive. Instead, we mounted the BTS on a pole, which we then mounted in a large tree with few branches. This is also shown in Figure 2. Other unrelated wireless equipment, which shares the local VSAT with other locations, is mounted on the same pole.

\subsection{Network Credits}

Unlike prior work [12, 26, 36], our network is for-profit; our users actively pay our NGO partner and affiliates to use it. We believe that local ownership (and local profit) incentivizes local actors to support the network; if local people profit from the network, they are more likely to care when it fails.

Most users in Indonesia use prepaid cellular plans. Local entrepreneurs sell network credits to users for a small premium, giving profit to both the network operator and these entrepreneurs. We built a similar system for the network in Desa. Users pay our NGO partner money for credits which they then use for communications.

Our NGO partners don't sell credits directly to potential users. Instead, they sell credits to a primary reseller, who then resells them to local merchants who resell to the users. These resellers (recruited by the primary reseller) set their own prices for credit sales. Each seller in that system makes a profit. The primary reseller only sells in bulk to the other sellers, who sell smaller amounts to local buyers. The sellers are, at this moment, only non-indigenous people, for a variety of reasons. First, they had the capital to invest (buy credits from the primary). Second, the two secondary sellers both own local stores that have power, allowing them to charge their phones. Third, a few of the Papuans with the capital and infrastructure to potentially sell credits have personal or political issues with MS. Lastly, the fact that anyone can do a credit transfer has not yet been publicly announced, keeping people from building smaller agencies. It is an explicit goal of MS and the researchers to involve local Papuans in this process, and we hope to do so in the future.

Interestingly, this was not the original system. We originally had an indigenous man (whose wife was a teacher at the school) as our only seller. This seller, like all teachers, lived on church property. The church took umbrage at us operating a commercial service on church grounds and forced him to stop. This happened when the researchers were away, and the primary reseller and MS decided to set up the current system without researcher participation.

\subsection{Software Components}

Our system is a modified version of the Village Base Station [17] (VBTS). VBTS is a set of extensions to OpenBTS [24] allowing for multimodal applications utilizing voice, text, and other mediums. This toolkit, in combination with FreeSWITCH, was used to build all of the services shown below. Our system also utilized some custom web components to speak with our SMS provider Nexmo. We leave a more detailed analysis of the architecture to future work.

\subsection{Services}

A full-scale cellular network provides a variety of functions including voice, SMS, and billing. In order to provide coverage in Desa, we implemented these and other services: provisioning new numbers, a pre-paid credit system (including credit check, transfer, and purchase), number checking, and delivery receipts.

\subsubsection{User Provisioning}

The first step in our system is the selling and provisioning of SIM cards to users. In GSM, SIM cards and phone numbers are different entities; they must be associated together by the network operator.

In our network, SIM cards were purchased from a vendor online and phone numbers are provided by Nexmo. The cheapest numbers provided by Nexmo are Swedish, which is what we sold to our users. We then use Nexmo to route communications (just SMS today) to the outside world. This means that all users in our network have Swedish phone numbers, not local Indonesian ones. The reasoning for this decision is described in more depth in $§ 6.2$.

\subsubsection{SIM Cards}

Our network provides standard 2G GSM coverage. This means that any existing GSM handset can connect to the network, assuming it has a valid SIM card. What SIMs can connect is a configuration setting in the BTS; we could require specific SIMs or accept any cards. We chose to manufacture our own SIM cards instead of utilizing the ones from existing carriers. Only our SIM cards can connect to the network in Desa. We did this to simplify the user's model of the network; when in Desa our SIM card works. When in the larger town, our SIM does not. SIM switching is common in the developing world [32] and Indonesia.

With this design choice made, we fabricated 1000 SIM cards (at US $\$ 0.65$ per card) and programmed them with the Indonesian Mobile Country Code (510) and our unique Mobile Network Code (55). This made certain that no other networks would accept our SIMs. Potential customers buy a SIM from our primary reseller at cost; the reseller makes no profit on that sale. This card is accompanied by documentation detailing the network, duration of service, our communication prices, and services in the network. The card is inserted into a user's phone and the seller provisions a new phone number that is then associated with that SIM.

Our SIM cards are sold with one year of coverage for 100000 Rupiah, approximately US\$10. This price covers one year of number rental from Nexmo (US\$0.65 per month) as well as the manufacturing of the SIM itself (US\$0.65); our NGO partner makes approximately US\$1.80 per SIM sold per year.

\subsubsection{Number Provisioning}

As mentioned above, we use Nexmo for outbound SMS service. We implemented a mechanism to automatically buy new numbers from Nexmo when provisioning a new SIM card. The system works as follows. When a new SIM card is purchased, it does not come with a set phone number. Instead, the seller places it in the customer's phone and immediately sends an SMS to 101 signaling their desire to join the network. The system queries our database of users and our stock of purchased Nexmo numbers. If there is an available number (i.e., purchased from Nexmo but not assigned to a user) we assign that to the user. If there is no such number available, we instead purchase a new number (at random) from Nexmo and assign that to the user. The user receives an SMS from 101 with their new phone number. The SIM seller is trained in this particular short code; it was not advertised to the community. 


\subsubsection{Credit System}

We utilize a pre-paid credit system similar to that used by other Indonesian cellular providers. To support this, we had to build services for users to buy, check, and transfer their credits.

\subsubsection{Credit Creation}

At the highest level, our NGO partner creates credits in the system to be sold to users for basic communications; they do this via a password protected web interface. This service was not originally written by us, but modified from Range Networks software. After credits are purchased by the primary reseller and added to their account, he or she uses our credit transfer service to resell to secondary sellers. The credit purchase website is only available to the owner of the network: our NGO partner.

\subsubsection{Credit Transfer.}

After credits are inserted into the primary reseller's account, they sell their newly acquired credits to secondary sellers via credit transfer. Likewise, these secondary sellers use the same system to transfer credits to actual users.

Credit transfer is initiated by sending a specially formatted SMS to the number 887. This format is TARGETNUMBER*AMOUNT. If the SMS is malformed, the user is sent a set of instructions. If the user has insufficient credit, a message informing them of this is sent. If correctly formatted, the user is given a short message detailing the transfer and asking for confirmation, with a four-digit confirmation code included. If they respond (again to 887) with the confirmation code, their transfer is completed and both the buyer and seller are sent a message indicating that the transfer was finished. All SMS are received by the users from the number 887 . The researchers or primary reseller instructed each secondary reseller on how to use the credit system. The service was initially kept from the public, but was advertised via broadcast SMS on May 7th.

\subsubsection{Credit Check}

To check their current credit level, a user of our system sends an SMS or call to 888. An SMS response is sent (even if they called) from 888 indicating their current credit level. The number 888 was selected because the national telecom provider uses this as their credit check number. This service was advertised to users on the paperwork provided with their SIM card.

\subsubsection{Basic Communications}

Our network provided both voice and SMS services locally, but only SMS service for outbound communication. The reasons for this are complicated. As mentioned in Section 6, interconnecting with other networks is very difficult. Interconnecting with both voice and SMS is even more difficult. As such, we quickly decided that we would only be able to provide one such service for bidirectional communication; users would either be able to SMS or call back and forth with their out-of-network friends.

We conducted a series of informal focus groups with people in Desa to decide if they would prefer outbound SMS or voice service. The results were surprising; though most users communicated primarily through SMS, they would prefer to have only voice service if they had to choose. The reasoning was that some contacts were voice-only (such as older family members) and they wanted the ability to communicate with those contacts.

At the same time, the limitations of our shared infrastructure were beginning to become apparent. SMS is asynchronous and can be delayed; voice requires significantly higher bandwidth and quality of service. We were unable to provide quality voice service without severely impacting other VSAT users or changing providers. As such, we decided to support only SMS for two-way out-of-network communications for now.

\subsubsection{Other Services}

We opened our network for beta testing in January of 2013. Ten key Desa community members, including missionaries, Papuans, and nonPapuan Indonesians, were invited to participate and given free SIM cards. On February 11 2013, the network opened for general use. During this time we monitored usage and conducted informal interviews. We discovered a few issues, and we implemented services to remedy these concerns.

\subsubsection{Number Check.}

First, users did not remember their phone numbers. This is likely a consequence of the fact that they had Swedish numbers; these were strange and did not look like traditional numbers. To resolve this, we implemented a service for checking your phone number.

A user sends an SMS or call to 889 requesting their current number in the system. An SMS response is sent (even if they called) from 889 giving their current phone number. 889 was chosen as it is close to 888 , and signals that it is a network service. The number check service was advertised on the paperwork provided when a user purchased a SIM card.

\subsubsection{Delivery Receipts}

The second issue we noticed was one of trust; users were often uncertain about the status of their messages. Indonesia is rife with SMS-based fraud, including spam and phishing. This fact, coupled with our strange Swedish numbers and the expectation that Desa lacked coverage, meant that many SMSs were initially ignored by recipients. Users did not know if the lack of response meant a network failure, a rejection by the receiver, or something else.

To remedy this, we implemented delivery receipts. Delivery receipts inform a user when an SMS has been delivered to the target. We chose to implement the service in an opt-in manner; users signal their participation and then all SMS are given receipts. This choice was made to again mimic the national carrier (or certain handsets), who also use an opt-in model.

To enable delivery receipts, a user sends an SMS to 300. They then receive an SMS from 300 signaling their participation. With delivery receipts enabled, a user would receive receipts again from 300 . To disable delivery receipts, a user sends an SMS to 301. As this issue was identified after service activation, delivery receipts were advertised via a broadcast SMS.

\subsection{Pricing}

In collaboration with our NGO partners, we set a pricing scheme for the basic services our system provides. We had three key goals. First, do not take a loss on any part of the system. This was because our technical partner, WC, was risk averse, having had numerous experiences where operations at a loss were abused by users. Second, we wanted to make a reasonable profit for the operator, MS. They were doing a lot of work and powering the equipment, so they wanted a return on that investment. Lastly (and in that order), we wanted to provide as much coverage as possible to the community.

Table 1 shows the result. Note that non-local calls are not yet implemented; this is due to limited VSAT capacity degrading call quality. These prices may seem high but are justified by the actual costs covered in the next section. They are also not far from those of early networks in Africa [18], which also had limited infrastructure and low population density. We hope to explore other pricing schemes and levels in future work. 
Table 1: Services supported, their prices, and usage rates.

\begin{tabular}{llll}
\hline Service & Shortcode & Price (US\$) & Usage (\%) \\
\hline Number & 101 & free & $100 \%$ \\
Delivery Receipt & $300 / 301$ & free & $17.1 \%$ \\
Credit Transfer & 887 & free & $24.6 \%$ \\
Credit Check & 888 & free & $91.4 \%$ \\
Number Check & 889 & free & $23.0 \%$ \\
Local SMS & - & $.02 / \mathrm{sms}$ & $82.4 \%$ \\
Global SMS & - & $.09 / \mathrm{sms}$ & $93.0 \%$ \\
Local Calls & - & $.02 / \mathrm{min}$ & $84.0 \%$ \\
\hline
\end{tabular}

\section{EVALUATION}

This system opened for customers on February 11th, connecting 187 subscribers by August 12th (Figure 3). To evaluate our system we gathered usage logs and user interviews. We first analyze the basic usage of the system, demonstrating a significant uptake. We then use these measurements, in combination with credit sales and operational costs, to show that the installation is sustainable and profitable for the local stakeholders. Lastly, we use user interviews to provide depth about the value the network provides to users, their concerns about its use, and their desires for future features.

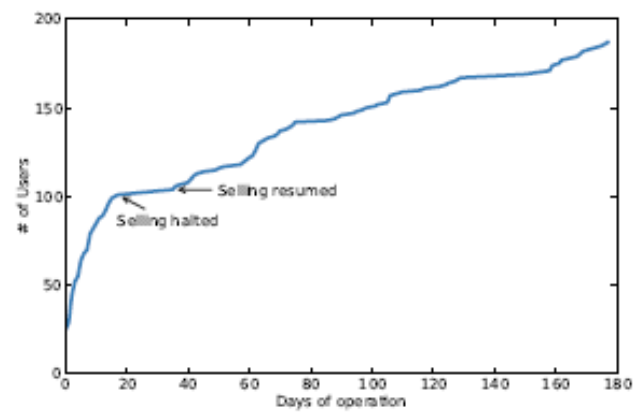

Figure 3: Number of users over time. Note the period of inactivity where selling was halted due to a shortage of numbers.

\subsection{Usage}

For billing and auditing purposes, we keep records of every call, SMS, and service usage. These timestamped records include the source and destination of every transaction, the transaction type, and any associated charges, allowing us to measure network usage.

Figure 4 shows usage of our most important service types over time. This figure excludes calls or SMS made in error (typically caused by attempting to call out-of-network numbers, which we do not support, or attempts made when the user's account was depleted) and use of free services like credit checks. Out-of-network SMS was by far the most popular service in our network, with over 1500 messages sent per week; SMS from out-of-network to our users ("incoming SMS") was tightly correlated with outgoing SMS frequency and comprised our second most popular service type. Local, in-network usage was typically lower, though in week 8 we saw a large spike in local usage, primarily driven by a sudden increase among a group of 5-10 users.

The preference for out-of-network communication seen in our network is not driven by a handful of heavy users; on the contrary, most of our users communicated more with out-of-network contacts than local ones. This distribution is shown in Figure 5. Notably, we had more than 10 users who only sent out-of-network SMS, and only 20 users who sent more local SMS than out- of-network SMS. This is despite the fact that out-of-network SMS costs over four times as much as local SMS.

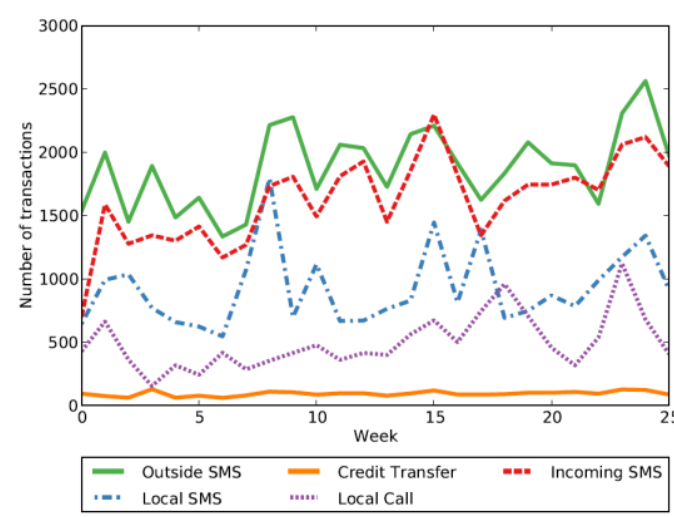

Figure 4: Per week overall usage of key service types. Out-ofnetwork messaging was most popular.

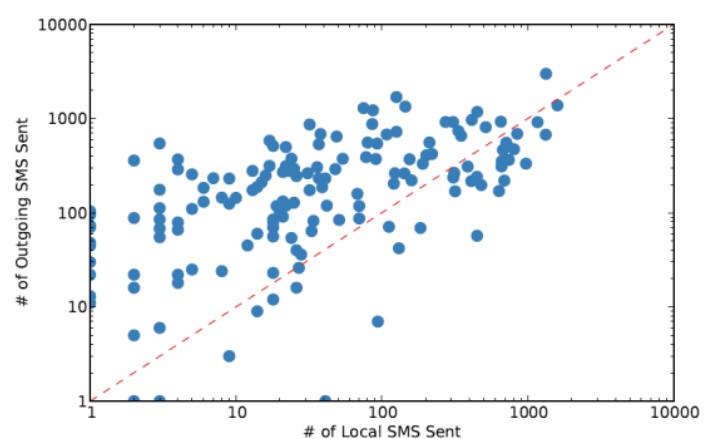

Figure 5: Comparison of in-network versus out-of-network SMS volume sent per user. Users tend to send more out- ofnetwork (i.e, outside Desa) messages than local ones; more than 10 users sent no local SMS messages.

Table 1 shows the proportion of users who used each network service at least once. $91 \%$ of users checked their account credit, the most popular network service. While all users received a credit transfer (that was the only way to purchase credits), $24 \%$ of users transferred credit to another user, despite it not being advertised until halfway through the study.

Table 2: Demographics of first 100 SIM card purchasers.

\begin{tabular}{ll}
\hline Origin & \\
\hline Non-Papua Indo. & $34 \%$ \\
Highliand Papuan & $54 \%$ \\
Coastal Papuan & $6 \%$ \\
Western & $6 \%$ \\
\hline
\end{tabular}

\begin{tabular}{ll}
\hline Gender & \\
\hline Male & $82 \%$ \\
Female & $18 \%$ \\
\hline
\end{tabular}

Table 2 shows user demographics for the first 100 SIM card sales. This data reflects individuals who bought a SIM card from the primary reseller; we have no way of knowing who actually used the SIM card once purchased. Although there is no census data to compare against, we believe non-Papuan Indonesians and Westerners are modestly overrepresented in the network, presumably because these groups tend to be wealthier. We observe a gender gap between male and female users exceeding the $17 \%$ gender gap seen in the rest of South East Asia [16]. At least part of this gap may be explained by men purchasing SIM cards on behalf of women. 
Table 3: System costs under shared-infrastructure and nonshared infrastructure models. The largest capital expenditure is the radio equipment, and the largest operational expenditure is the monthly cost of VSAT service for backhaul. Note that users paid US\$10.30 up-front for one year of both their phone number and SIM card.

\begin{tabular}{|c|c|c|c|}
\hline Item & Shared & Non-shared & Frequency \\
\hline BTS RF Equip. & US $\$ 5,400$ & US\$5,400 & One time \\
\hline BTS CPU & US\$100 & US\$100 & One time \\
\hline VSAT Equipment & US\$500 & US\$5,500 & One time \\
\hline Power & US $\$ 2,750$ & US $\$ 4,000$ & One time \\
\hline Cabling & US\$150 & US\$150 & One time \\
\hline Enclosures & US\$100 & US $\$ 100$ & One time \\
\hline VSAT Service & US\$15 & US $\$ 130$ & Per month \\
\hline Maintenance & US\$100 & US\$100 & Per month \\
\hline Phone Number & US\$0.65 & US\$0.65 & Per number-month \\
\hline Outgoing SMS & US\$0.01 & US\$0.01 & Per message \\
\hline SIM Card & US\$0.65 & US\$0.65 & Per card \\
\hline
\end{tabular}

\subsection{Sustainability}

One of our key goals was to demonstrate that small local cellular networks can be financially sustainable. We investigated this by performing an analysis of expenses, revenues, and profitability.

Table 3 describes both the capital and operational costs of the system. We consider two infrastructure models - one in which the network shares power and backhaul infrastructure with the community ("shared") and one in which there is no shared infrastructure ("nonshared"). We compute the cost of shared infrastructure as $5 \%$ of the capital costs of our partner's VSAT and micro hydro generator; nonshared infrastructure assumes independently purchasing a small VSAT and a solar system with sufficient battery capacity to power both the BTS and VSAT for two days without sunlight. The total capital cost associated with the shared model is US\$9,000, and the non-shared model US\$15,250. Maintenance covers wages for a parttime technician to maintain the system. Excluding VSAT service, other recurring costs are the same for both models.

The core components of the base station's cost are the radio and its associated amplifier and duplexer. However, as more companies enter the market for low-cost BTS radio equipment we expect the costs to fall. On the operational side, backhaul VSAT service was the largest expense. Although connecting a rural community cellular system to the outside world is challenging - typically expensive, lowperformance satellite connections are the only option - our usage results show that out-of-network communications are the most valuable to users in Desa. We also faced particularly high recurring monthly costs for phone numbers due to buying numbers at retail prices rather than on the wholesale market. Because of this, WamenaCom required users to prepay one year's worth of charges for their number. This ensures that we do not operate at a loss. Users will need to pay again each year to maintain service.

On the revenue side (Table 4), the highest grossing service was outof-network SMS, accounting for almost $90 \%$ of total revenue. Calls accounted for under $2 \%$ and the remaining revenue came from local SMS. Over the first 25 weeks of operation, the system grossed US\$5001.70, or approximately US\$830.65 per month. Our distribution of revenue per user is shown in Figure 6. Our median user spent US\$2.01 per month, and 93\% of users spent under US $\$ 15.00$ per month. Together, the top $10 \%$ of users accounted for $43 \%$ of revenue. Our average revenue per user per month (ARPU) was US\$4.44, compared to the ARPU for prepaid users of the largest Indonesian carrier Telkomsel of US\$3.60 [33].
Table 4: Number of usages of each service type for the period February 11th through August 12th. Revenue shown is for the network operator, and does not include reseller revenue.

\begin{tabular}{lrr}
\hline Usage Type & Amount & Revenue \\
\hline Outside SMS & 49,105 & US\$4,438.24 \\
Incoming SMS & 42,525 & - \\
Local SMS & 24,177 & US\$490.83 \\
Free SMS & 17,733 & - \\
Local Call & 12,965 & US\$72.63 \\
Free Call & 5,271 & - \\
Credit Transfer & 2,452 & - \\
\hline Total & $\mathbf{1 5 4 , 2 2 8}$ & US\$5,001.70 \\
\hline
\end{tabular}

Table 5 presents our projected monthly profit for the network under a variety of growth rates. While the network currently gains 17 users per month (excluding the first month of operation, which experienced rapid growth), we do not have sufficient data to project a long-term growth rate. Our model uses actual network revenues and costs for the first six months. For subsequent months, the projection assumes that current average monthly cash flow remains constant (i.e., usage patterns do not change) and that each new user will generate the current median monthly cash flow per user of US\$2.01. We further assume that capital costs are financed by a 5 year loan at $12.4 \%$ APR [35], paid monthly. Thus, the analysis allows for complete system replacement (including BTS, solar equipment, batteries, and VSAT) every 5 years. The system's current monthly profit using these assumptions is US\$368.31 and US\$66.43 under the shared and nonshared model, respectively.

Our profit estimates, combined with the system's ARPU, are key results. Local cellular networks have latitude to set prices appropriately to the costs of serving their area. In contrast, incumbent national providers must set prices uniformly across all their users and compete on a large scale. As an example, Telkomsel charges 150 rupiah per SMS to Indonesia, while our partners charge 900.

Table 5: Projected mean monthly profit over 5 years. Note that current growth rate is $\mathbf{1 7}$ users per month.

\begin{tabular}{lrr}
\hline Growth Rate & Shared & Non-shared \\
\hline 0 users / month & US $\$ 368.31$ & US\$66.43 \\
5 users / month & US $\$ 400.71$ & US $\$ 98.83$ \\
10 users / month & US\$433.11 & US $\$ 131.23$ \\
17 users / month & US\$478.47 & US $\$ 176.59$ \\
\hline
\end{tabular}

This may seem high, but other goods in Desa are similarly expensive: $1 \mathrm{~kg}$ of sugar is 25000 rupiah (vs. 8000 in Jayapura), $1 \mathrm{~kg}$ of rice is 20000 rupiah (vs. 5000), and $1 \mathrm{~kg}$ chicken is 65000 rupiah (vs. 14000). These prices put the system just above the break-even point under the non-shared infrastructure model. Meanwhile, the ability to share common infrastructure (as we shared power and backhaul connectivity with our local partner) substantially reduces costs, particularly capital expenditure. As a result, shared infrastructure networks are able to take advantage of the lower cost to operate more profitably in rural environments like Desa.

Last, we note that the network is also profitable for the local resellers (Table 6). It is hard to gauge the relative impact of these funds on the sellers. However, as each seller conducts numerous transactions every day, it is likely a valuable income source. 


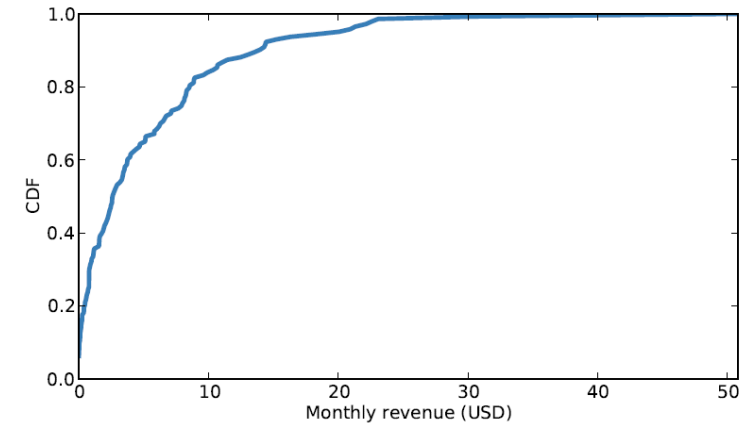

Figure 6: CDF of revenue per user per month. While $50 \%$ of users spent less than US\$2.01 per month, these users account for $7.7 \%$ of total monthly revenue; the top $10 \%$ of users account for over $\mathbf{4 0 \%}$ of monthly revenue.

Table 6: Income for credit resellers in dollars. Secondary 1 began sales on March 25 and Secondary 2 on April 3.

\begin{tabular}{lrrr}
\hline & Primary & Secondary 1 & Secondary 2 \\
\hline Amount Sold & US\$3,955.93 & US\$987.07 & US\$2,852.12 \\
Cost & US\$3,955.93 & US\$1,091.95 & US\$2,932.45 \\
Revenue & US\$4,177.24 & US\$1,177.45 & US\$3,303.93 \\
Avg. Markup & $5.6 \%$ & $19.3 \%$ & $15.8 \%$ \\
Profit per Month & US\$36.48 & US\$18.19 & US\$85.07 \\
Sales per Month & 9.7 & 71.1 & 290.4 \\
\hline
\end{tabular}

\subsection{Interviews}

Throughout the deployment, we conducted numerous design discussions with users. We also conducted formal interviews with 6 users in Desa, and a group of three people in Jayapura, the capital of the Province of Papua, who were in contact with users in Desa. One of the people in Jayapura is a resident of Desa. The formal interview targets were entirely indigenous Papuans, with five males and four females. Ages ranged widely, with two interviewees being students at the local government school (not MS), two being older church organizers, and the remaining five being adults. The interviews were done in Bahasa Indonesia and translated by a fluent speaker on our team, who also conducted the interviews. We first note the uptake of the service:

Interviewer: Among your friends in Desa, are many people using cards?

Garet: Oohhhh! Lots! You can see for yourself, right? Later, you can ask Matias, he is the one who sells [credits], there are already so many customers. The other day I saw the list, there are almost... 200 there. From the villages they also want to come buy.

We also sought to answer key questions about our intervention:

- How did the intervention benefit you and/or the community?

- How was the network used?

- What problems have you seen, or expect to see?

- What's your perspective on who owns the network? and

- What would you change about the network?

\subsubsection{Benefits}

The one message that permeated almost all of the interviews $(8 / 9$ of the formal) was the value brought to the community by the network. Users would make sure to mention their appreciation of what we have done and how important it is:
Benjamin: We are here as customers of WamenaCom, here in Distrik Desa. We are very grateful for the installation of the WamenaCom network. This is a very big change, an extraordinary change, it can build communication for these two districts. So I now say thank you just for this.

Garet: People have been coming and saying "Desa has a special network." So we are proud. This is one of the things that can bring us to be... advanced. Not like others, others use Telkomsel, we have a different network. This is what I was thinking. I felt very happy. So I was thinking, 'I don't have to go to Wamena anymore to send SMS, to phone in Wamena, I can relax here in Desa, sitting in the forest, roasting cassava.

Paulus: So generally people are happiest because now they know that Desa already has a network [that works]. So they can SMS to family in Desa, from there they can SMS to Jakarta, to anywhere, because Desa kids, many of them are taking studies in Jakarta, in Sentani here, in Manado, in Jogja, so parents are happy, because, right away, if one needs anything one simply contacts one's parents by SMS. So they are happy...

\subsubsection{Use}

Communication with family was incredibly important; every interviewee in Desa listed it as a primary use of the network. Leaving your home village for opportunities elsewhere is routine in Papua. Similarly, many non-Papuan Indonesians from nearby islands travel to Papua for work, including military service. These migrations, combined with strong familial bonds, led to this desire among our interviewees:

Garet: At the time of the [large social gathering], I already got my card. I sent SMSs, but I didn't send here, because I miss my family over there, I try sending SMS over there, and... to Wamena. So, I try like this, and eh! smooth!

Selina: With the younger sibling in Jayapura, as it happens she is now studying. So, she is still studying, and she is also in her final semester... We checked the developments, how is it, after long in Wamena, maybe is she sick, or what, tired. We asked like this, and are there any shortages or not, we checked so we can complete her needs. That's why we checked with the family that is over there.

Surprisingly, there was no discussion of business use of the network. This is likely a consequence of only interviewing Papuans, who own very little of the commercial infrastructure in Desa. Instead, two interviewees used it for local politics. As an example:

Selina: [Important politician] is my older male relative, so I follow developments: "how are things going?" and so on. If there are obstacles, challenges, we can support in prayer, so it is smooth.

Lastly, in-network communications were surprisingly common; two interviewees used them to organize activities in the village. This was unexpected, given the relatively small size of Desa. As one of the youths noted:

Interviewer: Why do you send SMS within Desa, even if it's close, you could speak directly, but you send SMS. What is the purpose?

Letty: Well, maybe, for example I'm at home, and I SMS a friend, or contact them, say "hey! please come pick me up, ok?". So we can go walking around.

\subsubsection{Problems}

Although local communications no doubt benefited the youth; others in the community were less optimistic about these messages. Two of 
the interviewees in Desa and one in Jayapura expressed concern about the youth dating, and the network's role in that:

Benjamin: People say having a network is a big change some older people say it is not so good. This difference between good and that bad or negative, the issue is that someone who already has a [cell phone] and has purchased this WamenaCom card, maybe they can send SMS like "OK how about we meet up" and so on with girlfriends or boyfriends.

and

Selina: But on the negative side, meaning, but even that, it all depends and returns to us. We parents, especially we parents who have sons and daughters who are teenagers, who all this time maybe have been under tight supervision by their parents, but now with WamenaCom being here, yes, maybe parents are not watching closely and children pull...

We note that this concern isn't about WamenaCom in particular, but rather an apprehension about mobile phones in general. Nor is it paranoia; some of our other interview targets spoke about contacting potential or existing romantic partners.

Lastly, we note that a few of the users did mention technical issues. One of the students was unable to communicate with anyone in Wamena, for some unknown reason, and this user was the only one to not speak highly of the network. There was also an issue one interviewee brought up with how users outside of the network understood our numbers, and sometimes confused them with spam:

Garet: I call my brother. So for instance I needed money, so I had to go through, communicate with them. But they didn't believe, because only SMS, even though I already gave them the number clearly and my identity clearly, so I went straight there, so then they believed.

\subsubsection{Ownership}

As our network is fairly untraditional, we were curious how the network ownership was viewed by the users. As the researchers spent months in the field and interacted with the population in Desa, we were well known. As one person noted:

Garet: Well [local person] said, the one who owns this network, is from... over there, they, this, team for what this network, this there is this guy who left already, right?

Interviewer: Kurtis?

Garet: Right.

Two other interviewees attributed ownership to the NGO that housed the equipment: Misionaris Sekolahin and its leader Regis.

Interviewer: [Who owns the network?]

Selina: All we know is, it's through uncle Regis. Through Regis, so... we are sure, because Regis is here, he is here together with us always, so we are sure, this is through Regis, so we believe, and we buy that card.

and

Paulus: Indeed, that day, I asked Garet, and he said, "Mr. Regis made this", he said that, Mr. Regis made it, not Telkomsel.

Lastly, one of the interviewees seemingly believed that the network was literally owned by the community:

Herman: Well according to me, this network, indeed, those who installed it, I don't really know, but it helps, so it's public.

Interviewer: Public, owned by the public?
Herman: Yes, it belongs to the public. Because at this time it is in Desa, so I think... people there use it, so it's publicly owned.

\subsubsection{Wants}

We also asked the users what future features were most important to them. The answer universally was voice service. When asked to justify this desire, respondents tended to answer in rather vague terms which suggested an intangible, affective value of communicating by voice as opposed to text. As an example, a prominent local organizer for a new political party went so far as to say that Desa needed voice service so the "voice of this rural area can be heard." We hope to deliver this service shortly.

\section{RISKS}

Section 5 showed that our particular deployment in Papua is beneficial and sustainable, but this doesn't mean that this would always be the case. Our experience exposed numerous challenges and conflicts that will likely emerge in any local cellular installation.

\subsection{Licensing}

GSM is licensed spectrum, meaning that to operate a GSM tower legally you must have government oversight and approval. Typical spectrum licenses are country-wide and cost billions of dollars. Though we have tacit approval from high-level members of the Indonesian government to operate the BTS, we do not have an actual license to operate in Indonesia. This means our installation is not, technically speaking, legal. Although the assurances we've been given reduce our risk of government interference, it is still present. Operating in a rural area also affects this risk. Papua, like many rural areas, has lax enforcement of wireless spectrum laws. In Desa, key authority figures from the police and military have expressed their acceptance of the installation, and local members of the security forces are among its most prolific users. As a result, our installation exists in an administrative grey zone, having achieved a degree of legitimacy even though the legal framework does not yet encourage decentralized mobile telephony networks. In general, spectrum licensing laws and enforcement vary greatly across nations, and any operator attempting to run a GSM network should be aware of the regulations in their area.

\subsection{Interconnect}

Though earlier work $[12,26,36]$ explored local-only networks, our usage indicates that out-of-network connectivity is a critical need for any local telco. Unfortunately, this is often not an easy task. In the cellular world, interconnection is a wild and woolly business, and who you know is as important as the services you bring. Being a small, independent rural operator is an extreme limitation in such an environment.

Originally, we had hoped to connect directly to a local Indonesian carrier. Meeting with these operators brought a lot of hope but few results. We tried tens of other SMS-routing companies, but none seemed to serve Indonesia well. It turns out that each company maintains multiple potential routes to Telkomsel, each with differing properties. Some could send to Telkomsel customers but not receive from them; others receive but not send. Still others could do both but the return phone number would be mangled or randomized to avoid spam filters.

We eventually ended up with Nexmo, the only company we found who could consistently route to Indonesia. Each provider connects different countries, so it's likely that an exhaustive search for the correct partner will be required whenever deploying in a new country. We hope that, given enough time and a large enough market, service providers will eventually value their breadth of countries enough to provide solid service across the board. 


\subsection{Theft}

Local ownership is supposed to reduce theft; stealing from people in your community who you know (and who know you) is much more dangerous than stealing from faceless corporations. We found this to be generally the case; no equipment was broken or stolen, nor was there any evidence of tampering. However, we had one instance of theft: a few users discovered how to generate counterfeit credits. The bug was quickly discovered and shut down.

Though we have yet to investigate this incident in depth, our feeling is that stealing digital items has less social stigma in our community. Our NGO partner has had to deal with similar issues in the past, such as tech-savvy users who were stealing Internet access. As such, theft of network service is likely to be a long-term concern for operators of networks like ours.

\section{DISCUSSION}

\subsection{Local Implications}

Although we describe our system as local, we wish to emphasize that it is not run by indigenous people. Both operating organizations, WC and MS, are run by non-Papuans; WC is run by an American technologist in Wamena. MS is run by an American couple who have lived in Papua for over a decade. We describe our project as "local" based on the fact that the tower is located within the community and operated by community members. Similarly, the operators are "locals" based on their long-term presence in, involvement in, and knowledge of Desa.

Being local does not mean that the technology or intervention will always benefit the community. Far from it - even "local" agents may be as destructive as any other. As an example, this system was deployed in partnership with an existing Papuan-run Christian mission. The long colonial history of Christian missions in Papua should not be ignored. Part of our work reinforces existing colonial power structures, potentially at the expense of indigenous ones. Though we believe very strongly in the good intentions of our missionary partners, this system could cause harm. Our goal in this work is to make cellular systems more accessible from a cost and technology perspective. Our belief is that this will enable more local, community-based actors to provide connectivity. Eventually, any group with sufficient will and a small amount of start-up capital will be able to run own networks; including groups with less resources and organizational capacity then WC and MS.

\subsection{Policy Support}

Substantive policy changes could reduce the risk for rural entrants and encourage innovation in small-scale telephony networks. We hope that our work, showing meaningful gains for rural users from local cellular networks, will positively benefit ongoing spectrum licensing reform movements. One approach is that of The Netherlands, which has set aside a portion of the DCS1800 band for unlicensed lowpower GSM networks [2]. More useful for rural areas would be setting aside the first five channels (ARFCNs) of the GSM900 band (less than $5 \%$ of that band) for unlicensed small-scale networks operating outside of existing coverage areas.

Similarly, the relatively low margins of small-scale cellular networks make them particularly sensitive to high interconnection fees which incumbent providers use to price out new competitors. Another (perhaps unintentional) barrier to entry for small operators is zealous blocking of SMS by incumbent providers to reduce spam; opaque blocking criteria and the difficulty of communicating with incumbent providers compounds this issue. Regulation to ensure fair interconnection with incumbent providers would be a major benefit for rural operators. These regulations exist in the US, and are a key reason for their relatively high number of rural operators.

\subsection{Generalizability}

Papua is a unique place in the world; there are few places with so many geographical obstacles to infrastructure development, so much natural wealth, and such wide cultural diversity. Because of this, we cannot know if our results will generalize to other parts of the world. The specific technologies (e.g., VSAT, wifi, hydro, solar) and specific social and technological structures (e.g., prepaid, prices, credit selling) used will no doubt depend on factors related to the target location. However, our design is based on a fundamental principle that does generalize: empowering local agents to solve their own communication problems with the materials and knowledge available in their community. For this reason, we believe our designs and technology will work in other areas, and plan to demonstrate that in future work.

\subsection{Alternative Models of Local Ownership}

Our deployment, being just one deployment, follows a simple model of local ownership; our partner organizations are led by individual immigrants to Papua. These leaders control the organizations completely; other members are employees or customers. Although this signals a limitation of our study, we believe our system could work with other organizational structures as well, such as cooperatives or franchisees. Grameen Telecom [4] used a franchisee model, but their phone ladies only had to buy phones and not base stations. Our franchisees would need more capital and technical capacity, but would also extend coverage (unlike Grameen).

Cellular networks, like many other kinds of infrastructure, are vital to the whole community. 187 people in Desa are customers of our service. We envision an alternative model: a cooperative network [13] where each member both owns and pays into the system. Rhizomatica [26] is an example: a community-owned OpenBTS-based network in Mexico. We envision services in the network that would support this vision of participatory governance; for example SMS voting and broadcasting community meetups. Our work is just a first step demonstrating the basic feasibility of small-scale local cellular networks, we plan to continue to explore supporting other models of ownership as we move forward.

\section{CONCLUSION}

Cellular networks cross the globe, covering billions of people. However, hundreds of millions of people still lack coverage. At least part of the reason is structural: traditional cellular networks are built top down, driven by profit motives of large carriers or by political pressures from governments. Areas that are less profitable or lack powerful politicians are often left without communications.

In this work, we proposed an alternative model for cellular systems: building them bottom up, with local people installing and operating smallscale, sustainable telecommunications firms leveraging local infrastructure when available. We evaluated this model by building and deploying a system in rural Papua, Indonesia in partnership with two local NGOs. We showed that such a system can generate a profit for local operators in a sustainable way and benefit the community by bringing important telecommunications to areas that do not have them. It is our belief this bottom-up model can bring cellular connectivity to those without coverage in a sustainable and profitable way for local communities.

\section{ACKNOWLEDGMENTS}

This work was supported in part by the Blum Center for Developing Economies, the Development Impact Lab (USAID Cooperative Agreement AID-OAA-A-12-00011), part of the USAID Higher Education Solutions Network, and a NSF Graduate Research Fellowship. We also thank our partners in Indonesia, including Onno Purbo, Yoe-One Ariestya Niovitta, Jerry Ng, everyone at MS, the community in Desa, and the wider missionary network in Papua. 


\section{REFERENCES}

[1] M. Adeyeye and P. Gardner-Stephen. The Village Telco Project: A Reliable And Practical Wireless Mesh Telephony Infrastructure. EURASIP J. Wireless Comm. and Networking, 2011:78, 2011

[2] Agentschap Telecom. Regeling gebruik van frequentieruimte zonder vergunning 2008. http://wetten.overheid.nl/BWBR0023553/volledig/geldigheids datum_23-04-2013, April 2013

[3] A. Agüero, H. de Silva, and J. Kang. Bottom of the Pyramid Expenditure Patterns on Mobile Services in Selected Emerging Asian Countries. Information Technologies \& International Development, 7(3), 2011

[4] Q. Alam, M. A. Yusuf, and K. Coghill. Village Phone Program, Commodification Of Mobile Phone Set And Empowerment Of Women. J. Community Informatics, 5(3-4), 2009

[5] A. Anand, V. Pejovic, E. M. Belding, and D. L. Johnson. Villagecell: Cost Effective Cellular Connectivity In Rural Areas. In Proceedings of the Fifth International Conference on Information and Communication Technologies and Development, ICTD '12, pages 180-189, New York, NY, USA, 2012. ACM

[6] BPS-Statistics Indonesia. http://www.datastatistikindonesia.com/. Retrieved 4/2013

[7] J. Burrell. Livelihoods And The Mobile Phone In Rural Uganda, January 2008. Report for the Grameen Foundation

[8] L. Butt. "Lipstick Girls" and "Fallen Women": AIDS and Conspiratorial Thinking in Papua, Indonesia. Cultural Anthropology, 20(3):412-442, Aug. 2005

[9] Competitive Carriers Association. http://competitivecarriers.org/. Retrieved 4/2013

[10] Deloitte. Economic Impact of Mobile in Bangladesh, Malaysia, Thailand, Pakistan, Serbia, and Ukraine, January 2008. A report prepared for Telenor ASA

[11] T. Egyedi and D. Mehos. Inverse Infrastructures: Disrupting Networks from Below. Edward Elgar, 2012

[12] V. Gabale, R. Mehta, J. Patani, K. Ramakrishnan, and B. Raman. Deployments made easy: essentials of managing a (rural) wireless mesh network. In Proceedings of the 3rd ACM Symposium on Computing for Development, DEV '13, pages 10:1-10:10, New York, NY, USA, 2013. ACM

[13] H. Galperin and F. Bar. The Microtelco Opportunity: Evidence from Latin America. In Information Technologies and International Development, volume 3, Winter 2006

[14] P. Gardner-Stephen and S. Palaniswamy. Serval mesh software-WiFi multi model management. In Proceedings of the 1st International Conference on Wireless Technologies for Humanitarian Relief, ACWR '11, pages 71-77, New York, NY, USA, 2011. ACM

[15] GSM Association. 3 Billion GSM Connections on the Mobile Planet. http://www.gsmworld.com/newsroom/pressreleases/2008/1108.htm

[16] GSM Association. Women and Mobile: A Global Opportunity. http://www.gsma.com/mobilefordevelopment/wpcontent/uploads/2013/01/GSMA_Women_and_MobileA_Global_Opportunity.pdf
[17] K. Heimerl and E. Brewer. The village base station. In Proceedings of the 4th ACM Workshop on Networked Systems for Developing Regions, NSDR '10, pages 14:1-14:2, New York, NY, USA, 2010. ACM

[18] K. Heimerl, R. Honicky, E. Brewer, and T. Parikh. Message Phone: A User Study and Analysis of Asynchronous Messaging in Rural Uganda. In SOSP Workshop on Networked Systems for Developing Regions (NSDR), 2009

[19] H. Horst and D. Miller. The Cell Phone: An Anthropology of Communication. Berg Publishers, October 2006

[20] International Telecommunication Union. Measuring the information society 2012. 2012

[21] International Telecommunications Union. Green Solutions to Power Problems (Solar \& Solar-Wind Hybrid Systems) for Telecom Infrastructure. http://www.itu-apt.org/gtas11/greensolutions.pdf. Retrieved 1/2013

[22] R. Jensen. The Digital Provide: Information (Technology), Market Performance, and Welfare in the South Indian Fisheries Sector. The Quarterly Journal of Economics, 122(3):879-924, 082007

[23] MCIT. USO 2012 Progress Update Indonesia. http://www.itu.int/ITU-D/asp/CMS/Events/2013/ASEANUSOF/Indonesia_country_report.pdf. Retrieved 4/2013

[24] OpenBTS. http://openbts.org. Retrieved 4/2013. [25] A. Ploeg

[25] Wealth items in the Western Highlands of West Papua. Ethnology, 43(4):291-313, 2004

[26] Rhizomatica. http://rhizomatica.org/. Retrieved 4/2013

[27] M. Ricklefs. A History of Modern Indonesia Since C. 1300. Stanford University Press, 1993

[28] D. Rutherford. Sympathy, State Building, and the Experience of Empire. Cultural Anthropology, 24(1):1-32, 2009

[29] A. Sen. Development As Freedom. Alfred A Knopf, Oct1999

[30] Statistics Indonesia. http://www.bps.go.id/eng.

[31] S. Surana, S. N. Rabin Patra, M. Ramos, L. Subramanian, Y. Ben-David, and E. Brewer. Beyond Pilots: Keeping Rural Wireless Networks Alive. In 5th USENIX Symposium on Networked Systems Design and Implementation, 2008

[32] E. Sutherland. Counting Mobile Phones, Sim Cards \& Customers. http://ssrn.com/abstract=1468847, 2009.

[33] Telkomsel. Telkomsel, 2011 annual report. http://www.telkomsel.com/media/upload/annualreport/AR_Tel komsel_2011_ENG_rev.\%2021Sept2012_Web\%20Version.pd f, September 2012.

[34] L. Waverman, M. Meschi, and M. Fuss. The Impact of Telecoms on Economic Growth in Developing Countries. Africa the impact of mobile phones, 2(1980):1-23, 2005

[35] World Bank. World Development Indicators 2012. https://openknowledge.worldbank.org/handle/10986/6014, 2012

[36] M. Zheleva, A. Paul, D. L. Johnson, and E. Belding. Kwiizya: Local Cellular Network Services in Remote Areas. In Proceedings of the 11th international conference on Mobile systems, applications, and services, MobiSys '13, New York, NY, USA, 2013. ACM 